Week4, 8, 12, 24 and 52 by LOCF method. Also we used ROC analysis in order to determine the optimal period to achieve remission for the DAS-ESR and SDAI at Week52.

Results: The group of patients included 16 males and 82 females. The mean age was $59.5 \pm 14.7$ years old; the disease duration was $9.4 \pm 8.8$ years; the patients of receiving methotrexate (MTX) was 73 cases (74\%); the MTX dose was $11.2 \pm 3.6 \mathrm{mg} /$ week and b-DMARD naïve patients was 57 cases $(61 \%)$. Clinical findings related to RA were as follows: mean tender joint count, $5.2 \pm 4.7$; swollen joint count, 5.0 \pm 4.0 ; patient's and physician's global assessment of disease activity, $48.9 \pm 27.4$ and $42.3 \pm 23.2 \mathrm{~mm}$; CRP, $1.9 \pm 2.2 \mathrm{mg} / \mathrm{dL}$; ESR, $47.4 \pm 34.0$ $\mathrm{mm} / \mathrm{h}$; MMP3, $233 \pm 186 \mathrm{ng} / \mathrm{ml}$; the rate of rheumatoid factor positive patients was $78 \%$; DAS28 (ESR), 4.84 \pm 1.36 ; and SDAI, 21.2 \pm 11.3 . The mean DAS-ESR improved to $3.54 \pm 1.35,3.31 \pm 1.46,3.37 \pm 1.47$ and $3.31 \pm 1.43$ at Week $4,12,24$ and $52(p<0.001, p<0.001, p<0.001, p<0.001)$ and the mean SDAl improved to $11.4 \pm 9.0,9.7 \pm 9.0,9.8 \pm 9.1$ and $9.4 \pm 9.1$ at Week $4,12,24$ and $52(p<0.001$, $\mathrm{p}<0.001, \mathrm{p}<0.001, \mathrm{p}<0.001$ ) significantly (Fig.1). At Week 4, 12, 24 and 52 the rate of patients who achieved remission were each $28.8,37.2,32.9,33.7 \%$ and $11.7,29.3,30.5,28.8 \%$ in DAS-ESR and SDAl criteria (Fig.2). Also at Week $4,12,24$ and 52 the rate of patients who achieved low disease activity (LDA) were each $46.6,53.2,51.2,55.8 \%$ and $58.8,64.1,65.9,71.3 \%$ in DAS-ESR and SDAI criteria. Areas under the receiver operating characteristic curves for the DAS28-ESR and SDAI at each time point for remision achievement at 52 weeks were each 0.578 and 0.702 at baseline, 0.755 and 0.822 at week4, 0.821 (cut-off index 2.73 , odds ratio 16.7 , sensitivity 0.75 , specificity, 0.85 ) and 0.856 (cut-off index 5.30 , odds ratio 29.6 , sensitivity 0.86 , specificity, 0.82 ) at week 8 , and 0.820 and 0.809 at week 12
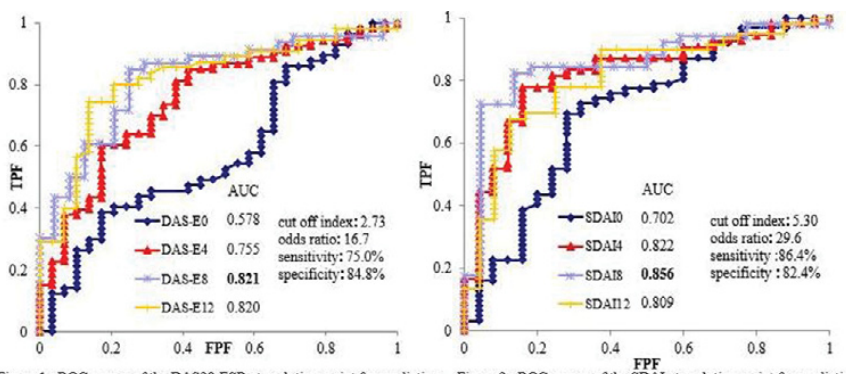

Figure 1: ROC curves of the DAS2s-ESR at each time point for predicting Figure $2:$ ROC curves of the SDA AI at each time point for predicting

Conclusions: The new TNF-antagonist therapy of CZP was effective early and rapidly in patients with active Japanese RA. This study suggested that eight weeks is an adequate optimal period to judge whether the achieved remission or not at Week 52

Disclosure of Interest: Y. Kanayama: None declared, A. Kaneko Speakers bureau: Mitsubishi Tanabe Pharma, Takeda Pharma, Eisai Pharma, Chugai Pharma, Abbott, Bristol-Myers Squibb, UCB, Janssen, and Pfizer, N. Takahashi Speakers bureau: Abbvie Japan Co. Ltd, Eisai Co. Ltd, UCB Japan Co. Ltd, MitsubishiTanabe Pharma Corporation, Takeda Pharmaceutical Company Ltd, Pfizer Co. Ltd, Chugai Pharmaceutical Co. Ltd, Janssen Pharmaceutical K.K., and, T. Kato: None declared, M. Hayashi: None declared, Y. Hattori: None declared, N. Asai: None declared, N. Ishiguro Grant/research support from: Daiichi Sankyo, Takeda Pharmaceutical, Hisamitsu Pharmaceutical, Otsuka Pharmaceutical, Taisho Toyama Pharmaceutical, Kaken Pharmaceutical, Eisai, Janssen Pharmaceutical, Bristol- Myers Squibb, AbbVie, Chugai Pharmaceutical, Mitsubishi Tanabe Pharmaceutical, Astellas Pharma, and Pfizer Japan, Speakers bureau: Daiichi Sankyo, Takeda Pharmaceutical, Hisamitsu Pharmaceutical, Otsuka Pharmaceutical, Taisho Toyama Pharmaceutical, Kaken Pharmaceutical, Eisai, Janssen Pharmaceutical, Bristol-Myers Squibb, AbbVie, Chugai, T. Kojima Speakers bureau: Mitsubishi Tanabe Pharma, Takeda Pharma, Eisai Pharma, AbbVie, Bristol-Myers Squibb, and Pfizer, Janssenn Pharmaceutical Companies, Astellas Pharma and Chugai Pharma

DOI: 10.1136/annrheumdis-2017-eular.4653

\section{SAT0175 A DESCRIPTIVE ANALYSIS OF REAL-WORLD TREATMENT PATTERNS IN A TURKISH RHEUMATOLOGY POPULATION THAT CONTINUED INNOVATOR INFLIXIMAB (REMICADE) THERAPY OR SWITCHED TO BIOSIMILAR INFLIXIMAB}

Y. Yazici ${ }^{1}$, L. Xie ${ }^{2}$, A. Ogbomo ${ }^{2}$, D. Parenti ${ }^{3}$, K. Goyal ${ }^{3}$, A. Teeple ${ }^{3}$, L. Ellis ${ }^{3}$ I. Simsek ${ }^{4}{ }^{1}$ New York University Hospital for Joint Diseases, New York; ${ }^{2}$ STATinMED Research Inc, Ann Arbor; ${ }^{3}$ Janssen Scientific Affairs, LLC, Horsham, United States; ${ }^{4}$ Guven Hospital, Ankara, Turkey

Objectives: This study examined treatment patterns in a rheumatology patient (pt) population initially prescribed innovator infliximab (IFX) that either switched to biosimilar infliximab (CT-P13) or continued on IFX following availability of CT-P13 in the Turkish healthcare system.

Methods: Adult pts with $\geq 1$ diagnosis code (ICD-10-CM M05.X; M06.X) for rheumatoid arthritis (RA) and a prescription for IFX were identified in a national Turkish health care database during the study period (01DEC2010-01DEC2015). Eligible pts were those who continued on IFX (Continuers cohort; CC) or switched from IFX to CT-P13 (Switchers cohort; SC) during the identification period; had continuous medical/pharmacy benefit enrollment $\geq 12$ months before and $\geq 6$ months after the index date (date of switch for SC and a random IFX prescription date for (C); had a prescription claim for IFX within 16 weeks of the index date during the baseline period. Demographics, concomitant disease, medications, and treatment patterns (dose, refill interval, discontinuation, and switch) were summarized. A confirmed discontinuation was defined as a switch to another biologic medication or the absence of an index biologic claim for $\geq 120$ days without censoring. Patient weight was unavailable in the dataset.

Results: Key results are shown in the Table. A total of 3018 pts met study criteria. The majority $(95 \%$; $n=2870$; CC) continued on IFX and had a mean age of 44 years; $46 \%$ were female and mean follow up of 12 months. A total of 148 pts (5\%) switched to CT-P13 (SC) and had mean age of 44 years; $51 \%$ female and mean follow up of 9 months. Approximately $40 \%$ of pts in each cohort had a concomitant diagnosis for ankylosing spondylitis (AS; Table). Other concomitant diseases and medications appeared balanced between cohorts. In the CC, pts had an average of 4.7 infusions at a mean dose of 4.4 vials approximately every 10 weeks. In the SC, pts had an average of 2.6 infusions at a mean dose of 3.6 vials approximately every 10 weeks. Therapy discontinuation occurred in $38 \%$ in the CC; average time to any discontinuation or censoring of IFX was 256 days (Table). In the SC, CT-P13 discontinuation was observed in $82 \%$; average time to any discontinuation or censoring of CT-P13 was 124 days; $74 \%$ of SC switched to another biologic with $94 \%$ of these returning to IFX.

\begin{tabular}{|c|c|c|c|c|}
\hline & \multicolumn{2}{|c|}{$\begin{array}{l}\text { Switchers Cohort } \\
(\mathrm{N}=148)\end{array}$} & \multicolumn{2}{|c|}{$\begin{array}{l}\text { Continuers Cohort } \\
(N=2870)\end{array}$} \\
\hline & N/Mean & $\% / S D$ & N/Mean & $\% / S D$ \\
\hline Age (Mean) (years) & 44 & 13 & 44 & 12 \\
\hline \multicolumn{5}{|l|}{ Gender } \\
\hline Female & 75 & $51 \%$ & 1,332 & $46 \%$ \\
\hline Average Length of Follow up Period (in Months) & 9 & 2 & 12 & 3 \\
\hline \multicolumn{5}{|l|}{ Concomitant Disease During Baseline Period } \\
\hline Ankylosing Spondylitis & 73 & $49 \%$ & 1,214 & $42 \%$ \\
\hline Psoriatic Arthritis or Psoriasis & 19 & $13 \%$ & 582 & $20 \%$ \\
\hline Crohn's Disease & 6 & $4 \%$ & 191 & $7 \%$ \\
\hline Ulcerative Colitis & 8 & $5 \%$ & 157 & $5 \%$ \\
\hline \multicolumn{5}{|l|}{ Concomitant RA-Medications During Follow-Up Period } \\
\hline Methotrexate & 31 & $21 \%$ & 652 & $23 \%$ \\
\hline Sulfasalazine & 21 & $14 \%$ & 340 & $12 \%$ \\
\hline \multicolumn{5}{|l|}{ Dosing Characteristics } \\
\hline Average \# of doses within follow up period & 2.6 & 1.6 & 4.7 & 2.4 \\
\hline Mean \# of weeks between doses & 10.1 & 5.1 & 9.9 & 3.8 \\
\hline Mean \# of days between 1 st and $2^{\text {nas }}$ dose & 75 & 48 & 70 & 34 \\
\hline Mean $\#$ of days between 2 nd and $3 r d$ dose & 72 & 38 & 70 & 29 \\
\hline Mean \# of days between $3 r d$ and 4th dose & 65 & 31 & 67 & 26 \\
\hline Mean \# of vials per Infusion & 3.6 & 1.6 & 4.4 & 1.9 \\
\hline \multicolumn{5}{|l|}{ Switching } \\
\hline$\#$ and $\%$ of patients with 21 switch & 110 & $74 \%$ & 471 & $16 \%$ \\
\hline$\%$ of Primary Switches from CT-P13 to IFX & 103 & $94 \%$ & NA & NA \\
\hline \multicolumn{5}{|l|}{ Discontinuation } \\
\hline \# of Patients Confirmed to Have Discontinued & 121 & $82 \%$ & 1,089 & $38 \%$ \\
\hline Time to confirmed discontinuation (days) & 94 & 58 & 126 & 91 \\
\hline Time to any discontinuation or censoring (days): & 124 & 87 & 256 & 138 \\
\hline
\end{tabular}

Conclusions: This study shows switching from IFX to CT-P13 was infrequent. However, in those switching to CT-P13, a high percentage (82\%) of CT-P13 discontinuation was observed and the majority returned to IFX. Further studies are needed to understand the reasons for these observations.

Disclosure of Interest: Y. Yazici Grant/research support from: Janssen Scientific Affairs, LLC, L. Xie Consultant for: Janssen Scientific Affairs, LLC, A. Ogbomo Consultant for: Janssen Scientific Affairs, LLC, D. Parenti Employee of: Janssen Scientific Affairs, LLC, K. Goyal Employee of: Janssen Scientific Affairs, LLC, A. Teeple Employee of: Janssen Scientific Affairs, LLC, L. Ellis Employee of: Janssen Scientific Affairs, LLC, I. Simsek Grant/research support from: Janssen Scientific Affairs, LLC

DOI: 10.1136/annrheumdis-2017-eular.1128

\section{SATURDAY, 17 JUNE 2017}

Rheumatoid arthritis - other biologic treatment

\section{SAT0176 PATTERNS OF BIOLOGIC DMARD MONOTHERAPY IN A LARGE NATIONWIDE RHEUMATOID ARTHRITIS COHORT: DATA FROM 1036 PATIENTS}

K. Thomas ${ }^{1}$, E. Kaltsonoudis ${ }^{2}$, A. Drosos ${ }^{2}$, I. Papalopoulos ${ }^{3}$, P. Sidiropoulos ${ }^{3}$, P. Katsimbri ${ }^{1}$, D. Boumpas ${ }^{1}$, P. Tsatsani ${ }^{4}$, S. Gazi ${ }^{4}$, E.P. Grika ${ }^{1}$,

P.G. Vlachoyiannopoulos ${ }^{1}$, K. Fragiadaki ${ }^{1}$, M. Tektonidou ${ }^{1}$, P.P. Sfikakis ${ }^{1}$, K. Karagianni ${ }^{1}$, L.I. Sakkas ${ }^{5}$, L. Pantazi ${ }^{6}$, K. Boki ${ }^{6}$, T. Dimitroulas ${ }^{7}$,

A. Garyfallos ${ }^{7}$, D. Kasimos ${ }^{8}$, G. Evangelatos ${ }^{9}$, A. lliopoulos $^{9}$, C. Georganas ${ }^{10}$, P. Vounotrypidis ${ }^{10}$, M. Areti $^{10}$, P. Georgiou ${ }^{11}$, K. Delis $^{10}, \mathrm{~K}_{\text {. Mavragani }}{ }^{1}$, I. Bournazos ${ }^{10}$, G. Katsifis ${ }^{12}$, C. Mavromatis ${ }^{10}$, G.D. Kitas ${ }^{13}$, D. Vassilopoulos ${ }^{1}$ 
Joint Rheumatology Program, University of Athens, Athens; ${ }^{2}$ University of Ioannina, Ioannina; ${ }^{3}$ University of Crete, Heraklion; ${ }^{4}$ KAT Hospital, Athens; ${ }^{5}$ University of Thessaly, Larissa; ${ }^{6}$ Sismanoglio Hospital, Athens; ${ }^{7}$ Aristotle University, Thessaloniki; ${ }^{8} 401$ General Military Hospital; ${ }^{9}$ NIMTS Hospital; ${ }^{10}$ Private practice, Athens; ${ }^{11}$ Agios Andreas Hospital, Patras; ${ }^{12}$ Rheumatology Unit, Naval Hospital; ${ }^{13}$ Hygeia Hospital, Athens, Greece

Background: There are limited literature data regarding the characteristics of rheumatoid arthritis (RA) patients treated with biologic DMARD (bDMARD) monotherapy.

Objectives: To evaluate the disease and treatment characteristics of RA patients treated with bDMARD monotherapy.

Methods: Multicenter, cross-sectional RA epidemiological study in Greece (06/2015-05/2016, ERE RA Study Group). Demographics, disease characteristics, treatment and co-morbidity data were collected via a web-based platform Results: 1036 RA patients treated with bDMARDs were identified during the one year recruitment period (female: $82 \%$, mean age: $61.5 \pm 13$ years, mean disease duration: $12.5 \pm 8.9$ years, mean DAS28-ESR: $3.4 \pm 3.3)$. Among them, $26 \%(n=273)$ were receiving bDMARDs as monotherapy and $8 \%(n=23)$ of them had never tried conventional synthetic DMARDs (csDMARDs) before; The latter group $(n=23)$ compared to the csDMARD-exposed $(92 \%, n=250)$ group, had more often co-morbidities [cardiovascular disease (22\% vs. $8 \%, p=0.029)$, chronic hepatitis ( $13 \%$ vs. $3 \%, p=0.02)$, hypertension $(57 \%$ vs. $38 \%, p=0.08)$, COPD $(13 \%$ vs. $4.4 \%, p=0.07)$ ] or were active smokers ( $41 \%$ vs. $14 \%, p=0.001)$. csDMARD discontinuation was mainly due to adverse events (AEs, 58\%) followed by inadequate response (IR, 44\%). Compared to the cs- and b-DMARD combination therapy group, monotherapy treated patients were more frequently seropositive ( $64 \%$ vs. $57 \%, p=0.003$ ), had lower DAS28-ESR ( 3.2 vs $3.5, p=0.009)$ and were more likely to have discontinued csDMARDs for AEs ( $58 \%$ vs. $21 \%, \mathrm{p}<0.001)$ or IR $(44 \%$ vs. $27 \%, p<0.001)$. Tocilizumab $(22.3 \%$ vs. $12.7 \%, p<0.001)$ and rituximab $(19.8 \%$ vs. $13.5 \%, p=0.013)$ were utilized more often, whereas adalimumab less often $(8.8 \%$ vs. $14.8 \%, p=0.012)$ as monotherapy compared to as part of combination therapy.

Conclusions: In our large RA cohort, one out of four bDMARD treated patients, were receiving bDMARDs as monotherapy. Co-morbidities rather than RA characteristics influence the initial decision for bDMARD monotherapy whereas among those starting combination cs- and b-DMARD therapy, the majority discontinue csDMARDs due to AEs.

Acknowledgements: Grant support from the Hellenic Rheumatology Society and Professional Association of Rheumatologists.

Disclosure of Interest: None declared

DOI: 10.1136/annrheumdis-2017-eular.4390

\section{SAT0177 SAFETY EVENTS ARE SIMILAR WITH ABATACEPT VS PLACEBO TREATMENT IN RA: RESULTS FROM INTEGRATED DATA ANALYSIS FROM NINE CLINICAL TRIALS}

B. Soule $^{1}$, M. Hochberg ${ }^{2}$, D. Fleming ${ }^{1}$, A. Torbeyns ${ }^{1}$, T. Simon ${ }^{1}$, S. Banerjee ${ }^{1}$, M. Boers ${ }^{3} \cdot{ }^{1}$ Bristol-Myers Squibb, Princeton; ${ }^{2}$ University of Maryland, Baltimore, United States; ${ }^{3} \mathrm{VU}$ University Medical Center, Amsterdam, Netherlands

Background: Abatacept is a selective co-stimulation modulator that consists of the extracellular domain of human cytotoxic T lymphocyte-associated antigen-4 linked to the modified $\mathrm{Fc}_{\mathrm{c}}$ portion of human immunoglobulin and was approved initially for the treatment of RA in 2005. The integrated safety database for abatacept in adult RA comprises data from short- and long-term periods of 16 open-label and double-blind RA clinical trials, and combines studies of both IV and SC abatacept involving 7044 total patients. Of these, data from the 9 double-blind, placebo-controlled studies involving 4138 total patients were included in this analysis. The most recent overall safety analysis was performed in 2012 and reported IV and SC results separately.

Objectives: To provide an update of the overall abatacept safety profile based on data analysis from both IV and SC trials.

Methods: This evaluation included all patients with RA enrolled in 9 key doubleblind, placebo-controlled clinical trials of IV and/or SC abatacept. The safety analysis includes all serious adverse events (SAEs), as well as AEs of interest including infections, malignancies and autoimmune diseases.

Results: In total, 2653 patients were exposed to abatacept and 1485 received placebo. During the double-blind, controlled period, the mean (SD) duration of exposure was 10.3 (3.5) months for the placebo group and 10.8 (3.3) months for the abatacept group for a total exposure of 2357 and 1254 patient years, respectively (Table 1). The proportion of patients as well as incidence rates for death, SAEs, infections, malignancy and autoimmune diseases were similar between those treated with abatacept and placebo (Table 2).

Conclusions: In a large RA clinical trial database, safety events including deaths, serious infections, opportunistic infections, malignancies and autoimmune diseases occurred at similar frequencies and rates in the abatacept and placebo treatment groups.

Disclosure of Interest: B. Soule Employee of: Bristol-Myers Squibb, M. Hochberg Shareholder of: Theralogix LLC, Grant/research support from: $\mathrm{NIH}$, Consultant for: Bristol-Myers Squibb, EMD Serono Inc., Genentech/Roche, Novartis Pharma AG, Pfizer Inc, UCB Inc., D. Fleming Employee of: Bristol-Myers Squibb, A. Torbeyns Shareholder of: Bristol-Myers Squibb, Employee of: Bristol-Myers Squibb, T.
Table 1. Demographic Data

\begin{tabular}{lcc}
\hline & Abatacept $(\mathrm{N}=2653)$ & Placebo $(\mathrm{N}=1485)$ \\
\hline Mean age, yr (SD) & $51.7(12.4)$ & $51.4(12.3)$ \\
Female, \% & 79.1 & 79.7 \\
White, \% & 86.1 & 86.5 \\
NSAIDs, \% & 79.0 & 79.6 \\
Glucocorticoids, \% & 51.6 & 49.4 \\
Mean oral dose, mg (SD) & $7.5(8.1)$ & $9.1(9.1)$ \\
MTX, \% & 68.2 & 63.8 \\
Anti-TNF, \% & 6.4 & 5.5 \\
\hline
\end{tabular}

Table 2. Events During the Double-Blind, Placebo-Controlled Period

\begin{tabular}{lcclcc}
\hline & \multicolumn{2}{c}{ Abatacept $(\mathrm{N}=2653)$} & & \multicolumn{2}{c}{ Placebo $(\mathrm{N}=1485)$} \\
\cline { 2 - 3 } \cline { 6 - 6 } Outcome & $\mathrm{N}(\%)$ & $\mathrm{IR}(95 \% \mathrm{Cl})$ & & $\mathrm{N}(\%)$ & $\mathrm{IR}(95 \% \mathrm{Cl})$ \\
\hline Deaths & $12(0.5)$ & $0.5(0.3,0.9)$ & & $12(0.8)$ & $1.0(0.5,1.7)$ \\
SAEs & $331(12.5)$ & $14.8(13.3,16.5)$ & & $174(11.7)$ & $14.6(12.5,17.0)$ \\
Discontinued due to SAEs & $68(2.6)$ & & & $22(1.5)$ & \\
Infections & $1440(54.3)$ & $91.3(86.7,96.2)$ & & $761(51.6)$ & $90.8(84.4,97.4)$ \\
Serious infections & $41(1.5)$ & $1.7(1.2,2.3)$ & & $16(1.1)$ & $1.2(0.7,2.0)$ \\
Solid organ malignancies & $26(1.0)$ & $1.11(0.7,1.6)$ & & $12(0.8)$ & $1.0(0.5,1.7)$ \\
NMSC (combined) & $14(0.5)$ & $0.6(0.3,1.0)$ & & $5(0.3)$ & $0.4(0.1,0.9)$ \\
Autoimmune diseases & $198(7.5)$ & $8.5(7.3,9.8)$ & & $115(7.7)$ & $9.2(7.6,11.1)$ \\
COPD & $13(0.5)$ & $0.6(0.3,1.0)$ & & $2(0.1)$ & $0.2(0.0,0.6)$ \\
\hline
\end{tabular}

Simon Shareholder of: Bristol-Myers Squibb, Employee of: Bristol-Myers Squibb, S. Banerjee Shareholder of: Bristol-Myers Squibb, Employee of: Bristol-Myers Squibb, M. Boers Consultant for: Bristol-Myers Squibb

DOI: 10.1136/annrheumdis-2017-eular.2383

\section{SAT0178 PULMONARY INVOLVEMENT IN RHEUMATOID ARTHRITIS TREATED WITH BIOLOGIC}

E. Guerrero ${ }^{1}$, M.L. García ${ }^{1}$, E. Galindez ${ }^{1}$, E. Ruíz ${ }^{1}$, I. Torre ${ }^{1}$, L. Estopiñan ${ }^{1}$, O. Fernández ${ }^{1}$, A. Inchaurbe ${ }^{1}$, C. Perez $^{1}$, J. Blanco $^{1}$, I. Calvo ${ }^{1}$,

O. Ibarguengoitia ${ }^{1}$, N. Rivera ${ }^{1}$, I. Gorostiza ${ }^{2}$ on behalf of Rheumatology Service. ${ }^{1}$ Rheumatology Service; ${ }^{2}$ Research Unit, Basurto Hospital, Bilbao, Spain

Background: Use of biologic therapy (BT) has been determinant in Rheumatoid Arthritis' (RA) change of management and outcomes improvement for the last decade. Classic extraarticular manifestations are now uncommon, except for the pulmonary involvement, which can occur due to different causes and can complicate our patients' treatment and prognosis.

Objectives: The aim of this study is to evaluate the presence of pulmonary complication in RA patients under BT in our hospital, and assess its severity and the modifications required.

Methods: Review of clinical records of 208 RA patients receiving BT in the last 5 years (January 2012 to December 2016). 23 cases of preexisting lung disease for other causes have been excluded and finally 26 patients have been finally included. Demographic data, characteristics of RA, types of pulmonary involvement, evolution and changes in treatment have been collected. Statistical analysis were performed using SPSS v22.

Results: $73.1 \%$ are women, mean aged 59 years (31-80); $53.8 \%$ never smokers. They suffer from long term RA (median 176.92 months, SD 199.34); only 2 patientes have been recently diagnosed (less than a year). They are mainly seropositive (85\% RF positive) with positive CCP antibodies in $69.2 \%$, and with erosive disease in $70 \%$. $25 \%$ have other extraarticular manifestations (3 rheumatoid nodules, 4 cardiac involvement).

Half of the patients were in remission or low activity (DAS 28) at the time of pulmonary disease diagnosis, and the median of CRP was $0.52 \mathrm{mg} / \mathrm{dL}$ (SD 1.72). $90 \%$ had received Methotrexate and almost half of them Leflunomide; $30 \%$ had been treated with BT (50\% TNF alpha inhibitors).

Intersticial lung disease (ILD) was the most frequent pulmonary involvement $(57.7 \%)$ and non-specific intersticial pheumonia (NSIP) the most prevalent pattern $(>60 \%)$. We also found obstructive pulmonary disease $(11.5 \%)$ and vascular involvement $(7.7 \%) .40 \%$ of the patients had a normal radiograph (all of them a pathological CT)

Treatment was modified in $53.8 \%$ of the cases (synthetic DMARD was kept in $68 \%$ and $\mathrm{BT}$ in $64 \%$ ).

The average time of evolution of pulmonary involvement is 37.85 months (1-156). $80 \%$ of the patients kept stable or improved from their arthritis and also from respiratory disease. Only one received a lung trasplant and another one died.

We haven't found an association between different types of pulmonary involvement and the different variables analyzed in the study. We didn't show significant differences in prognosis related to pulmonary disease distinct patterns; up to $80 \%$ of patients with ILD stabilize or improve.

Conclusions: Prevalence of pulmonary disease in our experience in RA patients under BT is similar to prevalence in other observational studies $(10-20 \%)$, because diagnosis here is due to casual detection in a routine chest X-ray or for clinical suspicion for respiratory symptoms (cough, dyspnea, ...). The evolution has been good perhaps for the high prevalence of NSIP, which requires less therapeutic intervention. Protocols for systematic search of lung disease in RA patients seem essential for its proper diagnosis, and there is a need for further research in pathogenesis and management of this complication. 